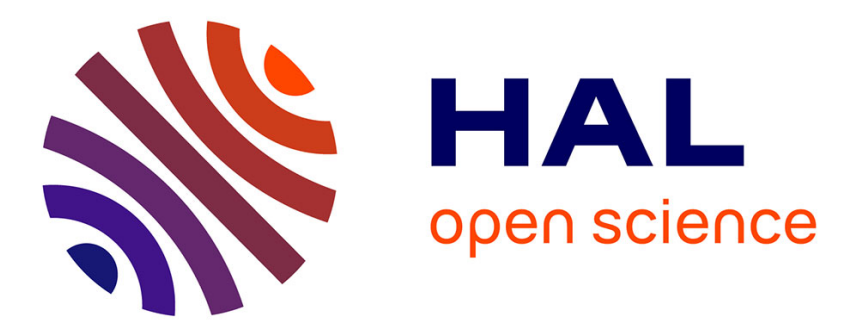

\title{
Surface band structure of aryl-diazonium modified p-Si electrodes determined by X-ray photoelectron spectroscopy and electrochemical measurements
}

Thomas Cottineau, Mario Morin, Daniel Belanger

\section{- To cite this version:}

Thomas Cottineau, Mario Morin, Daniel Belanger. Surface band structure of aryl-diazonium modified p-Si electrodes determined by X-ray photoelectron spectroscopy and electrochemical measurements. RSC Advances, 2013, 3 (45), pp.23649. 10.1039/c3ra44366c . hal-02384187

\author{
HAL Id: hal-02384187 \\ https://hal.science/hal-02384187
}

Submitted on 28 Nov 2019

HAL is a multi-disciplinary open access archive for the deposit and dissemination of scientific research documents, whether they are published or not. The documents may come from teaching and research institutions in France or abroad, or from public or private research centers.
L'archive ouverte pluridisciplinaire HAL, est destinée au dépôt et à la diffusion de documents scientifiques de niveau recherche, publiés ou non, émanant des établissements d'enseignement et de recherche français ou étrangers, des laboratoires publics ou privés. 
Cite this: DOI: $10.1039 / \mathrm{c3ra} 44366 \mathrm{c}$

Received 14th August 2013

Accepted 1st October 2013

DOI: $10.1039 / c 3 r a 44366 c$

www.rsc.org/advances

\title{
Surface band structure of aryl-diazonium modified p-Si electrodes determined by X-ray photoelectron spectroscopy and electrochemical measurements $\dagger$
}

\author{
Thomas Cottineau, \$ Mario Morin and Daniel Bélanger* \\ The influence of grafted organic layers, obtained by aryldiazonium cations reduction, on the surface \\ properties of p-type silicon was investigated. These layers were characterized by X-ray photoelectron \\ spectroscopy (XPS), infrared spectroscopy and electrochemical methods. The results indicate a \\ passivation of the silicon surface, a decrease of the oxidation of silicon. The results from electrochemical \\ and XPS measurements can be used together to quantify the shift of the surface energy bands of the \\ semiconductor caused by the presence of these layers at the surface. These measurements are \\ important to understand the interfacial properties of the semiconductor and this grafting method can \\ thus be used to adjust the surface energy levels positions toward those of different chemical reactions.
}

\section{Introduction}

The surface properties of semiconductors and their modification by organic molecules is of great importance for development of emerging applications in the domain of electronic devices, biosensors or for solar energy conversion in photovoltaic or photoelectrochemical cells. ${ }^{1-3}$ For all these applications it is of great interest to develop methods to obtain, easily and with reduced cost, covalent bonds between the semiconductor and organic molecules. ${ }^{4}$

Amongst semiconductors, silicon is used in the industry of electronic and photovoltaic cell since more than fifty years and a large amount of work was dedicated to the study of its surface properties and stability. ${ }^{5}$ In order to chemically control the surface of silicon a common method is the chemical etching in fluoride containing solution. ${ }^{6}$ It allows the preparation of silicon surfaces free of any trace of oxide and passivated with a relatively stable monolayer of $\mathrm{Si}-\mathrm{H}$ bonds. ${ }^{7}$ This layer provides excellent surface properties to silicon like a slow surface recombination of charge carriers. ${ }^{8}$ Nevertheless, the surface passivated by $\mathrm{Si}-\mathrm{H}$ is not fully stable and silicon oxide appears within a few hours. ${ }^{9}$ The chemical modification of the silicon surface with grafted organic molecules could be interesting to improve its stability. ${ }^{1}$

Département de Chimie, Université du Québec à Montréal, succursale centre-ville, Montréal, Québec, H3C 3P8, Canada. E-mail: belanger.daniel@uqam.ca; Fax: +1514-987-4054; Tel: +1-514-987-3000 ext. 3909

$\dagger$ Electronic supplementary information (ESI) available: Overlayer model used for XPS calculation. XPS C 1s core level spectra. Detailed Mott-Schottky Analysis. Detailed calculation for energy diagram of semiconductor/electrolyte interface. See DOI: $10.1039 / \mathrm{c} 3 \mathrm{ra} 44366 \mathrm{c}$

\$ Current address: Institut de Chimie et Procédés pour l'Énergie, l'Environnement et la Santé (ICPEES), Université de Strasbourg/CNRS, 67087, Strasbourg, France.
Furthermore, the grafting of molecules on semiconductor surfaces can be used to achieve a one-step passivation and functionalization of the surface. ${ }^{\mathbf{1 0}}$ It can be an attractive method to develop new applications relying on the engineering of the interface. For instance the molecules can serve as anchoring site for bioactive species to develop biosensors. ${ }^{\mathbf{1 1}}$ These interfaces can also be used to develop hybrid organic/inorganic electronic devices or for strong covalent interactions between polymer and inorganic particles. ${ }^{12}$

For all these applications, the control of surface state density, the tuning of the electron affinity, beside the limitation of the oxide formation, is important. ${ }^{13}$ The grafting of molecules can be used to adjust these parameters depending of the type of molecule grafted. For instance, this approach was used to modify the electron affinity of GaAs of $1 \mathrm{eV}$ by grafting tartaric acid derivative with different substituent on the benzene group. ${ }^{\mathbf{1 4}} \mathrm{A}$ similar but weaker effect was observed for silicon surfaces modified by electrochemical reduction of diazonium species. ${ }^{13}$ The modification of these surface properties is of great importance for photoelectrochemical applications like water splitting ${ }^{3}$ or $\mathrm{CO}_{2}$ photoreduction. ${ }^{15}$ Indeed, the surface energy level of the semiconductor valence and conduction bands might be modified by this method to match, or at least get closer to, the standard potential of the desired redox reactions. The measurement of the surface properties of silicon is usually conducted by X-ray and UV photoelectron spectroscopies (XPS, UPS), photoluminescence (PL) and photovoltage methods. ${ }^{13,16}$

Many routes exist for chemical grafting of molecular species on silicon surfaces. ${ }^{1}$ Amongst them, the use of radical species is often reported since radicals can be generated at ambient condition in liquid or gaseous phases. ${ }^{17}$ For instance, the modification of a silicon surface by grafting using the electrochemical reduction of aryldiazonium salt has been conducted recently with the objective 
to passivate the silicon surface..$^{13,18,19}$ The aryldiazonium salt chemistry for surface modification, first described by Pinson and co-workers, ${ }^{20}$ is now quite common since diazonium salts are easily and rapidly prepared in one step from a wide range of anilines. ${ }^{21}$ Furthermore, this technique allows the covalent attachment of aryl groups bearing functionalities such as alkyl, nitro, cyanide, carboxylic, ester, alcohol, thiol and halogenated groups to various surfaces (metals, semiconductors, textiles...). ${ }^{\mathbf{1 1 , 2 2}}$

In this work, we investigated the modification of p-type silicon surface by electrochemical grafting from aryldiazonium cations and the influence of the grafted layers on the surface properties, particularly on the passivation of silicon and on the position of energy levels in surface. Modified p-Si electrodes were characterized by X-ray photoelectron and infrared spectroscopies to monitor the grafting of the different species and the modification of silicon surfaces. Electrochemical methods were used to obtain information on the electronic properties of the modified surface and on the charge transfer at the semiconductor-electrolyte interface. A whole interface band model is proposed from these results combining analysis techniques in high vacuum (XPS) and in solution (electrochemistry) which are more representative of the real working conditions of the system, for instance in photoelectrochemical applications. ${ }^{\mathbf{1 3 , 2 3 , 2 4}}$

\section{Experimental details}

\subsection{General information}

All cleaning and etching reagents were of electronic grade and used without further purification. Ultrapure water was provided by a Millipore station, which ensures a resistivity of $18.2 \mathrm{M} \Omega \mathrm{cm}$. All solutions were bubbled under $\mathrm{N}_{2}$ for at least $30 \mathrm{~min}$. in order to remove dissolved $\mathrm{O}_{2}$. Hereafter, unless specified, all potentials are reported versus the Normal Hydrogen Electrode (NHE).

\subsection{Preparation of the silicon surface}

Silicon samples were cut from p-type Si (111) wafers $(\rho=1-10 \Omega$ $\mathrm{cm}$; SQI) and cleaned by ultrasonic baths in acetone, methanol and water ( $5 \mathrm{~min}$. for each solvent) to remove organic contamination. Then, the samples were etched in a diluted HF (1\%) solution in order to remove the native oxide layer. A subsequent cleaning was done in "piranha" solution $(1: 1$ concentrated $\mathrm{H}_{2} \mathrm{SO}_{4}-\mathrm{H}_{2} \mathrm{O}_{2} ; 90{ }^{\circ} \mathrm{C} ; 10 \mathrm{~min}$ ) in order to remove all organic and metallic contaminations and generate a sacrificial oxide layer. This wet oxidation was followed by rinsing with ultrapure water. The cleaned silicon samples were then chemically etched in an ammonium fluoride solution $\left(\mathrm{NH}_{4} \mathrm{~F} 40 \%\right.$; under $\mathrm{N}_{2}$ bubbling) to remove sacrificial oxide and form a flat hydrogenated silicon surface. ${ }^{25}$ After etching, the surface was quickly rinsed with ultrapure water and dried under $\mathrm{N}_{2}$ flux.

\subsection{Modification of the silicon surface}

Functionalization of the surface by an organic layer was done by electroreduction, in a three-electrode cell, of aryl diazonium cations dissolved in $0.1 \mathrm{~mol} \mathrm{~L}^{-1} \mathrm{H}_{2} \mathrm{SO}_{4}$. An $\mathrm{Ag} / \mathrm{AgCl}$ (saturated $\mathrm{KCl})$ electrode was used as reference $(0.199 \mathrm{~V} v s$. NHE) and a platinum mesh as the counter electrode. The working electrodes consisted of the freshly hydrogenated silicon samples and their electroactive area was defined by an O-ring $\left(0.49 \mathrm{~cm}^{2}\right)$. Commercially available 4-nitrobenzene diazonium tetrafluoroborate (hereafter noted NBD; Aldrich) was used as received. Amino terminated aryldiazoniums, were in situ generated from $p$-phenylenediamine (PPDA; 99\% Aldrich), 4-aminobenzylamine (ABA; 99\% Aldrich) and 4-(2-aminoethyl)aniline (AEA; 97\% Aldrich) as described in a previous study. ${ }^{26}$ The structure of the precursors corresponding to the different grafted molecules is represented in Scheme 1.

The diazotation was conducted by reaction of the arylamine molecules with one equivalent of $\mathrm{NaNO}_{2}$ (90\%; Aldrich) in $0.1 \mathrm{~mol} \mathrm{~L}^{-1} \mathrm{H}_{2} \mathrm{SO}_{4}$ for $10 \mathrm{~min}$. before the grafting. The diazotation reaction occurs according eqn (1):

$$
\mathrm{NH}_{2}-\mathrm{C}_{6} \mathrm{H}_{4}-\mathrm{R}+\mathrm{NO}_{2}^{+} \rightarrow \mathrm{N}_{2}^{+}-\mathrm{C}_{6} \mathrm{H}_{4}-\mathrm{R}+\mathrm{H}_{2} \mathrm{O}
$$

As soon as the cell is filled with the electrolyte $\left(0.1 \mathrm{~mol} \mathrm{~L}^{-1}\right.$ $\left.\mathrm{H}_{2} \mathrm{SO}_{4}\right)$, the electrode was kept at a potential $(-0.1 \mathrm{~V} v s$. NHE) in the dark to prevent the oxidation of silicon. The diazonium ions solution was added to the electrolyte to reach a final concentration of $2 \times 10^{-3} \mathrm{~mol} \mathrm{~L}^{-1}$. Following grafting, the electrodes were ultrasonicated for $10 \mathrm{~min}$. in acetonitrile to remove physisorbed molecules.

\subsection{Characterization methods}

Infrared spectra were collected on a Nexus 670 FTIR spectrometer (Nicolet) equipped with a MCT detector (resolution $1 \mathrm{~cm}^{-1}$ ) in attenuated total reflectance (ATR) mode with a custom designed crystal older. A p-type Si (111) crystal $(25 \times$ $10 \times 3 \mathrm{~mm} ; 45^{\circ}$; Medway Optics), cleaned according the previously described method, was analyzed at the different steps of the cleaning and grafting procedures. All measurements were performed in a dry $\mathrm{N}_{2}$ atmosphere at $20^{\circ} \mathrm{C}$.

$\mathrm{X}$-ray photoelectron spectroscopy (XPS) measurements were carried out with an Axis-165 from Kratos Analytical equipped with an $\mathrm{Al}$ anode $\left(\mathrm{Al} \mathrm{K}_{\alpha}\right.$ at $\left.1486.6 \mathrm{eV}\right)$. Data were recorded with an energy pass of $20 \mathrm{eV}$ for core level spectra and $80 \mathrm{eV}$ for survey spectra. The operating pressure in the analysis chamber was always kept below $10^{-9}$ Torr. All samples have to be sent out for analysis and were typically analysed between 4 and 7 days after preparation. All binding energies were referenced to that<smiles>Nc1ccc(N)cc1</smiles>

PPDA<smiles>NCc1ccc(N)cc1</smiles>

ABA<smiles>NCCc1ccc(N)cc1</smiles>

AEA<smiles>[NH3+]c1ccc([N+](=O)[O-])cc1</smiles>

\section{NBD}

Scheme 1 Chemical structure of the molecules used for the modification of $\mathrm{Si}$ surfaces. Aromatic diamines before diazotization reaction (PPDA, ABA, AEA) and nitrobenzene diazonium (NBD) cations. 
of adventitious carbon binding energy at C $1 \mathrm{~s}=284.9 \mathrm{eV}$. Representative C 1s core level spectra are presented for the various surfaces in ESI; Fig. S1. $\dagger$ Data treatment and peak-fitting procedures were performed using CasaXPS software with relative sensitivity factors corresponding to the Kratos spectrometer. An evaluation of the thickness of the grafted layer can be obtained using the overlayer model (see details in ESI $\dagger$ ). ${ }^{27}$ The oxide thickness was measured by the model proposed by Seah et $a .^{28}$ and some samples were also analysed by angle resolved XPS measurements at $\theta=0$ and $60^{\circ}$ for comparison.

The electrochemical measurements were performed in a three-electrode cell connected to a potentiostat (Solartron 1470) coupled to a frequency response analyzer (Solartron 1255B). The counter electrode was a Pt mesh, and the reference electrode was an $\mathrm{Ag} / \mathrm{AgCl}$ electrode. Electrochemical impedance spectroscopy measurements were performed in a $1 \mathrm{~mol} \mathrm{~L}^{-1} \mathrm{HClO}_{4}$ solution to minimize surface anions absorption and in the dark to avoid the parasitic hydrogen evolution reaction. Experiments were conducted in a frequency range of $0.5 \mathrm{~Hz}$ to $500 \mathrm{kHz}$ with potential ranging from -1.3 to $0.7 \mathrm{~V} v s$. NHE and perturbation amplitude of $\pm 10 \mathrm{mV}$.

\section{Results and discussion}

\subsection{Modification of the electrode with an organic layer}

The modification of hydrogen passivated p-type silicon with the diazonium chemistry was conducted potentiostatically by electrochemical reduction. ${ }^{29}$ Typical current-time curves are presented in Fig. 1. A current spike followed by a rapid decrease of the current is observed when the diazonium ions solution is injected in the electrolyte ( 0 of time axis). The charge corresponding to the area of this peak is related to the amount of diazonium cations reduced to aryl radicals and nitrogen according to the following mechanism: ${ }^{30}$

$$
\begin{gathered}
\mathrm{N}_{2}{ }^{+}-\mathrm{C}_{6} \mathrm{H}_{4}-\mathrm{R}+\mathrm{e}^{-} \rightarrow \mathrm{C}_{6} \mathrm{H}_{4}-\mathrm{R}+\mathrm{N}_{2} \\
\mathrm{Si}-\mathrm{H}+\mathrm{C}_{6} \mathrm{H}_{4}-\mathrm{R} \rightarrow \mathrm{Si}+\mathrm{H}-\mathrm{C}_{6} \mathrm{H}_{4}-\mathrm{R} \\
\mathrm{Si}+\mathrm{C}_{6} \mathrm{H}_{4}-\mathrm{R} \rightarrow \mathrm{Si}-\mathrm{C}_{6} \mathrm{H}_{4}-\mathrm{R}
\end{gathered}
$$

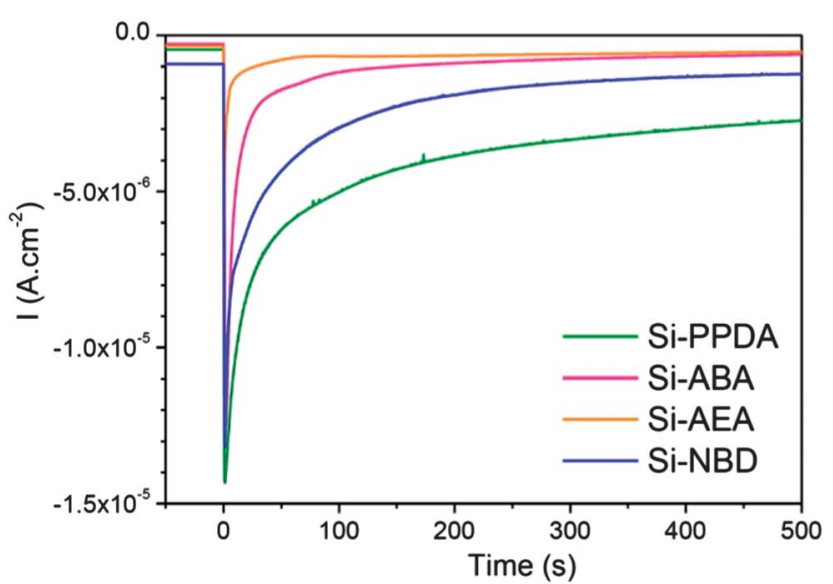

Fig. 1 Current-time transient during the electroreduction at $-0.1 \mathrm{~V}$ for grafting of different aryl groups (see Scheme 1) in the dark.
The grafting process occurs in two steps. A first radical is used to remove hydrogen from the silicon surface to form a dangling bond (eqn (3)) that reacts with a second aryl radical to yield a Si- $\mathrm{C}_{6} \mathrm{H}_{4}$ bond (eqn (4)). This scheme is idealized and the free radicals can react in different ways before removal of terminal hydrogen atoms from the silicon surface. For instance, some radicals can react to capture a proton from the electrolyte or in a radical-radical interaction in solution to form dimers $\mathrm{R}-$ $\mathrm{C}_{6} \mathrm{H}_{4}-\mathrm{C}_{6} \mathrm{H}_{4}-\mathrm{R}$.

Practically, the grafting yield is not $100 \%$ due to these different parasitic reactions and to the surface physisorbtion of some phenyl molecules or oligomers. These physisorbed species can be removed by ultrasonication in acetonitrile. The grafting of the layer occurs readily upon polarization and for longer modification time, thicker layers are obtained as the generated diazonium radicals can react with the already grafted phenyl groups. Fig. 1 shows a decrease of the transient current and the charge consumed for the different arylamines deposition when the length of aliphatic chain is longer. These observations will be discussed later and correlated with the film thickness of the grafter layer.

The grafted aryl layers were characterized by ATR infrared spectroscopy. The hydrogenated silicon surface obtained after the cleaning treatment on the ATR silicon crystal was used as background spectrum. The reflectance spectrum obtained after the grafting of a nitrobenzene layer is presented in Fig. 2. Different characteristic vibration bands appear on this spectrum. The intense asymmetric and symmetric stretching bands of the $\mathrm{NO}_{2}$ groups are visible at 1523 and $1348 \mathrm{~cm}^{-1}$, respectively. The band at $1598 \mathrm{~cm}^{-1}$ is attributed to the $\mathrm{C}-\mathrm{C}$ stretching of the phenyl ring. The vibrational bands of phenyl groups are also visible at 3110 and $3081 \mathrm{~cm}^{-1}\left(\nu_{\mathrm{s}}\right.$ and $\nu_{\text {as }}$ of $\left.\mathrm{C}-\mathrm{H}\right)$.

The presence of these bands confirms that grafting occurred. Two aliphatic C-H group bands are visible at 2964 and $2933 \mathrm{~cm}^{-1}$ $\left(\nu_{\mathrm{s}}\right.$ and $\nu_{\text {as }}$ of $\left.\mathrm{C}-\mathrm{H}\right)$. These contributions are always observed and

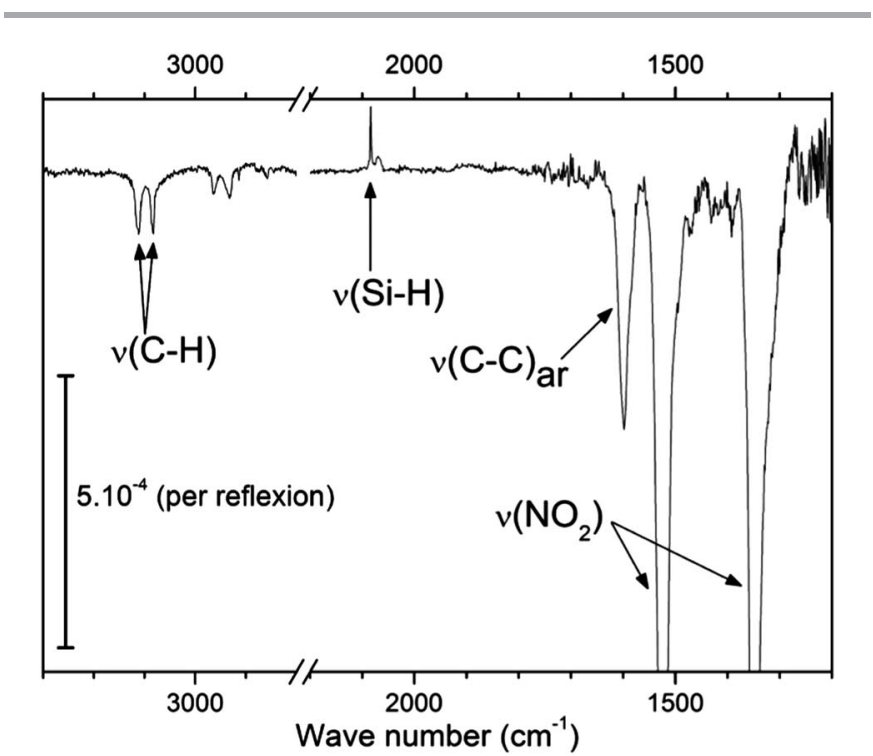

Fig. 2 Reflectance spectrum obtained after silicon surface modification with a nitrobenzene-grafted layer. 
are due to pollution present on the apparatus optics that is not fully compensated by the background correction. Since the absorption coefficient of aliphatic $\mathrm{C}-\mathrm{H}$ bonds is much larger than that of aromatic ones, their surface concentration is therefore much smaller. ${ }^{31}$ The positive peak at $2083 \mathrm{~cm}^{-1}$, indicating the disappearance of the $\mathrm{Si}-\mathrm{H}$ bond, is another evidence of the attachment of the organic layer in surface. The small width of this peak $\left(<2 \mathrm{~cm}^{-1}\right)$ is a proof of the homogeneity and the flatness of the hydrogenated surface obtained after the cleaning treatment. ${ }^{25}$ Nevertheless, the small peak located at $2070 \mathrm{~cm}^{-1}$ indicates the presence of multihydrides or other monohydrides sites (coupled $\mathrm{H}-\mathrm{Si}-\mathrm{Si}-\mathrm{H}$ or $\mathrm{H}$ attached to $\mathrm{Si}$ in an arrangement different than for bulk Si). These sites can be due the surface misorientation of the crystal used for ATR leading to the appearance of edge and terraces.

\subsection{X-ray photoelectron spectroscopy analysis}

XPS survey spectra of unmodified and modified silicon surfaces are presented in Fig. 3a. The comparison of spectra from oxidized $\mathrm{Si}$ sample $\left(\mathrm{Si} / \mathrm{SiO}_{2}\right)$ and the sample after the etching procedure $(\mathrm{Si}-\mathrm{H})$ indicates a decrease of $\mathrm{O} 1 \mathrm{~s}(530 \mathrm{eV})$ and $\mathrm{C} 1 \mathrm{~s}$ $(285 \mathrm{eV})$ peaks. At the same time, the Si 2p contribution increases as a result of the partial removal of surface oxide and carbon contamination. After grafting of a nitrobenzene layer, the intensity of the $\mathrm{C} 1 \mathrm{~s}$ and $\mathrm{O} 1$ s peaks increases significantly and a N 1s peak appears around $400 \mathrm{eV}$. Consequently, the Si 2p and $\mathrm{Si} 2 \mathrm{~s}$ contributions are strongly decreased due to the attenuation effect of the organic layer grafted in surface.

Information on the silicon surface oxidation state can be obtained from XPS Si 2p core level spectra. In addition to the characteristic Si $2 \mathrm{p}_{3 / 2}$ and $2 \mathrm{p}_{1 / 2}$ (99.3 and $99.9 \mathrm{eV}$ ) doublet, a broad peak attributed to silicon oxide appeared around $103.5 \mathrm{eV}$
(Fig. 3b). The ratio between these two contributions is a good indicator for the amount of the surface oxide. After the etching procedure, i.e. after $\mathrm{Si}-\mathrm{H}$ formation, the $\mathrm{O} / \mathrm{Si}$ ratio is $3.9 \%$ (Fig. 3b, top). Angle resolved XPS measurements allow an evaluation of the oxide layer thickness and this ratio of $3.9 \%$ corresponds to a thickness of $1.8 \pm 0.5 \mathrm{~nm}$. A comparable value of $2.0 \pm 0.7 \mathrm{~nm}$ is obtained by considering the intensities of the Si doublet peak and the peak of silicon oxides by using the method described by Seah et al. ${ }^{28}$ It should be noted that this sample was analyzed four days after the $\mathrm{Si}-\mathrm{H}$ formation, whereas the electrochemical measurements discussed in the last part were conducted directly after the sample preparation. The amount of surface oxide is probably less in this last case. After one month of air exposure (Fig. 3b, bottom), the ratio increases to $19.8 \%$. In this case, an oxide thickness of $4.2 \pm 1.6$ $\mathrm{nm}$ is evaluated. Interestingly, when a grafted layer is present, after two months of air exposure, the ratio reaches only $9 \%$ (corresponding to $2.2 \pm 1.1 \mathrm{~nm}$ ) and $11 \%(2.6 \pm 1.2 \mathrm{~nm})$ in the case of aminobenzyl and nitrobenzene layers, respectively. These results indicate the passivation of the electrode when a grafted layer is present. The organic layer partially prevents oxidation upon exposure to air. Presumably, this could limit the charge carrier recombination due to surface states induced by the presence of oxide. Nevertheless, there is a high uncertainty on the oxide thickness measurements by this method. It should be noticed that the model used for calculation is valid for flat and homogenous oxide layer. In our case, an oxidation starting at defects of the grafted layer, which can lead to oxide islands expanding laterally under the coating, cannot be excluded. ${ }^{29}$

A close examination of the $\mathrm{N} 1 \mathrm{~s}$ core level spectra area reveals the presence of different contributions depending on the grafted molecule (Fig. 3c). In case of nitrobenzene, the peak located at $406.1 \mathrm{eV}$ is characteristic of nitro groups and the second peak at
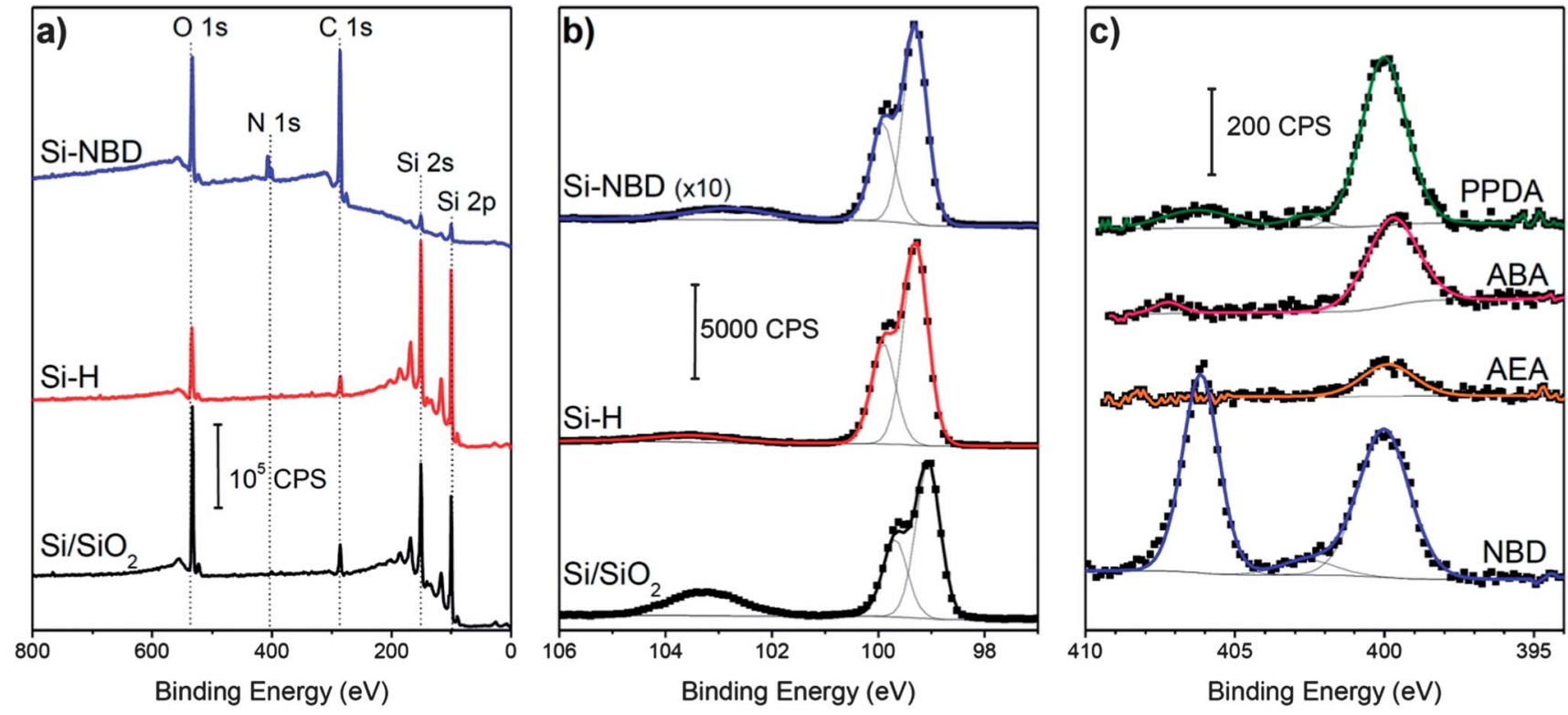

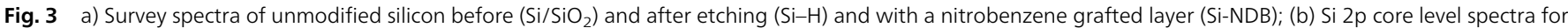

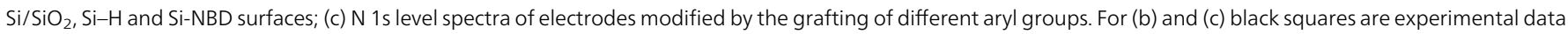
and colored lines represent the curve-fitting results. 
$400.0 \mathrm{eV}$ can be attributed to hydroxylamine or amino groups. ${ }^{32}$ The acidic medium and the applied negative potential (near the reduction potential of $\mathrm{NO}_{2}$ groups) during the grafting can induce the electrochemical reduction of nitro groups explaining the presence of the low binding energy peak. A third peak which appears as a shoulder at $402.5 \mathrm{eV}$ could be attributed to ammonium species formed during the cleaning of the sample with water $\left(\mathrm{p} K_{\mathrm{a}}=9\right){ }^{26}$ The presence of azo bridges formed between two aryl groups $\left(\mathrm{Si}-\mathrm{C}_{6} \mathrm{H}_{4}-\mathrm{N}=\mathrm{N}-\mathrm{C}_{6} \mathrm{H}_{4}\right)$ or with the surface $\left(\mathrm{Si}-\mathrm{N}=\mathrm{N}-\mathrm{C}_{6} \mathrm{H}_{4}\right.$ ) cannot be excluded as their contributions appear in the same binding energy range (400-402 eV). ${ }^{34}$ No adsorption of diazonium salt on the grafted organic film occurs as indicated by the absence of the characteristic peaks for the diazonium functionality at 403.8 and $405.1 \mathrm{eV} \cdot{ }^{35}$ In the case of the grafting of an arylamine, the main contribution located at $399.9 \mathrm{eV}$ is attributed to the amine groups. ${ }^{26}$ The decrease of the $\mathrm{N}$ 1s peak intensity when the aliphatic chain is longer is a first qualitative indication of the efficiency of the grafting.

Maximal and minimal thickness values of the different grafted layers are calculated from the overlayer model and reported in Table 1 with the corresponding equivalent number of monolayer. In all cases the grafting of at least a monolayer is obtained. A decrease of the thickness is found when the carbon chain between the phenyl and amino group is increased, as previously observed for ABA and AEA. ${ }^{26}$ Table 1 also reports the charge used for reduction of diazonium cations calculated from the currenttime transient curves presented in Fig. 1. As the length of the aliphatic chain increases, a decrease of the reduction charge is observed. From the charge and the thickness of the resulting organic films, an approximate grafting yield for the different diazonium ions can be calculated and is reported in Table 1. Despite that a thinner AEA layer is generated, the grafting yield of this arylamine molecule with an aliphatic chain is larger than for aminophenyl molecules (PPDA). The results indicate an increase of the grafting yield from 0.2 to 0.9 when the length of the aliphatic chain increases. For comparison, the grafting by electrochemical reduction of nitrobenzene diazonium cations led to the formation of a multilayer, with a lower yield of $0.2-0.3$. These results can possibly be explained as follows. Firstly, if the dipole moment on the different diazonium molecules differs, then the orientation of the molecules when they reach the surface could not be optimal (for instance if the diazo functionality is not

Table 1 Comparison of charge used for grafting, layer thickness and grafting efficiency for different aryl diazonium modified silicon surfaces

\begin{tabular}{lllll}
\hline & PPDA & ABA & AEA & \multicolumn{1}{l}{ NBD } \\
\hline Charge, $q,\left(\mathrm{mC} \mathrm{cm}^{-2}\right)$ & -3.36 & -0.73 & -0.18 & -0.81 \\
Radicals per adsorbate site, $n_{x}{ }^{a}$ & 54 & 12 & 3 & 13 \\
Film thickness (max-min), (nm) & $5.7-3.6$ & $2.2-1.1$ & $1.2-0.6$ & $1.9-1.0$ \\
Film thickness (max-min), (mL) $^{b}$ & $8.4-5.3$ & $3.2-1.7$ & $1.7-0.8$ & $2.8-1.5$ \\
Grafting yield $^{c}$ & $0.2-0.1$ & $0.4-0.2$ & $0.9-0.6$ & $0.3-0.2$
\end{tabular}

${ }^{a}$ One absorption site is defined as the surface unit mesh of a superstructure comprising two silicon atoms. For $\mathrm{Si}$ (111) the adsorption site density is $3.9 \times 10^{14} \mathrm{~cm}^{-2} .^{33} b$ One monolayer is assumed to have a thickness of $0.67 \mathrm{~nm}^{.9}{ }^{c}$ The grafting yield is the number of phenyl attached on the surface per generated radical. The calculation is done according to the mechanism of eqn (2)-(4). directed towards the surface) for efficient grafting. ${ }^{36}$ The same effect of the dipole moment is possible for the radical species that bind to the surface. However, a more probable explanation is related to the reactivity of the diazonium cations. ${ }^{22,26}$ The thicker film obtained for aminophenyl-modified p-Si is believed to be due to the more positive reduction potential of the corresponding diazonium ions relative to the reduction potential of diazonium ions with an aliphatic amine. ${ }^{26 c}$ In our work, a relatively low potential of $-0.1 \mathrm{~V} v s$. NHE was selected for electrografting on p-Si. In these conditions, it is unlikely that the grafting of AEA and ABA is performed under diffusion-controlled conditions and more likely in the activated potential region.

\subsection{Electrochemical analysis of the interface}

Electrochemical measurements provide information on the effect of surface modification on the p-Si surface properties. Capacitance versus potential curves, shown in Fig. 4, were obtained for different electrodes from electrochemical impedance spectroscopy measurements carried out at $500 \mathrm{~Hz}$ in $1 \mathrm{~mol}$ $\mathrm{L}^{-1} \mathrm{HClO}_{4}$. With the native oxide layer, a broad peak appears around $0.2 \mathrm{~V}$, before the capacitance rise due to the accumulation of holes at the semiconductor-electrolyte interface. This peak is characteristic of intermediate electronic states induced by the presence of surface oxide. ${ }^{37}$ After the cleaning treatment, the peak of surface states is strongly reduced but still present at $0.1 \mathrm{~V}$. In this case, the surface states can be due to the weak passivation by $\mathrm{Si}-\mathrm{H}$ bonds and also because silicon oxidation occurs during the electrochemical measurements when the potential is increased to more positive values.

Following surface modification with arylamines (AEA, ABA and PPDA), the signature of surface states is strongly suppressed, confirming the passivation of silicon electrodes as already observed by XPS. In the case of the grafting of a nitrobenzene layer, a broad peak attributed to the reversible electrochemical reduction of the surface nitro groups in

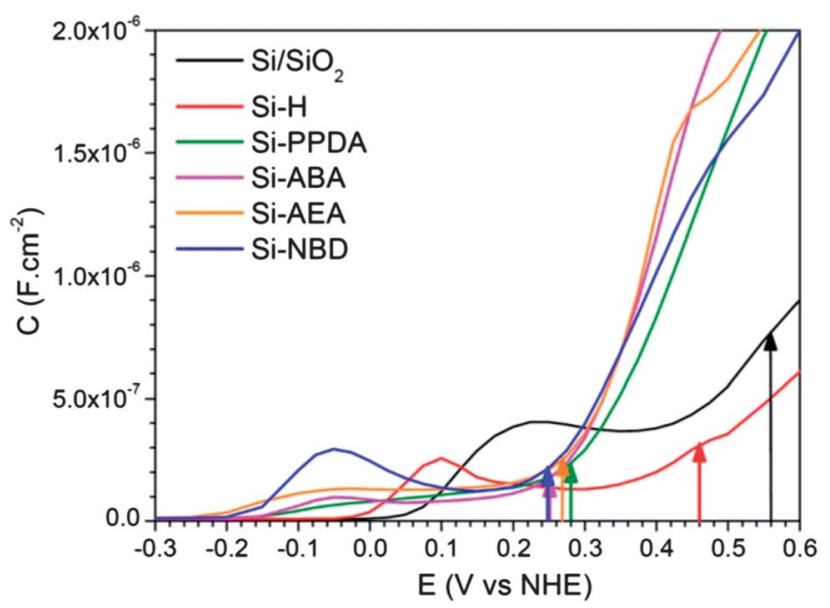

Fig. 4 Capacitance-potential plot $\left(f=500 \mathrm{~Hz}\right.$ ) obtained in $1 \mathrm{~mol} \mathrm{~L}^{-1} \mathrm{HClO}_{4}$ for as-received $\mathrm{p}$-Si electrode $\left(\mathrm{Si} / \mathrm{SiO}_{2}\right)$, after etching $(\mathrm{Si}-\mathrm{H})$ and after electrografting aminophenyl (Si-PPDA), p-aminobenzyl (Si-ABA), p-aminoethylphenyl (Si-AEA) and nitrobenzene (Si-NBD) groups. The vertical arrows indicate the flat band potentials $E_{\mathrm{fb}}$ determined from Mott-Schottky plots. 
hydroxylamine appears at $-0.05 \mathrm{~V}^{38}$ The presence of these electroactive groups was confirmed by XPS.

Data from electrochemical impedance spectroscopy are also used to obtain Mott-Schottky plots for each electrode (details are given in ESI $\dagger$ ). The flat-band potentials, $E_{\mathrm{fb}}$, and charge carrier densities, $N_{\mathrm{a}}$, for the different modified and unmodified silicon surfaces are estimated using the linear domain where the Mott-Schottky relation (ESI, $\uparrow$ eqn (3)) is valid. The values are reported in Table 2 and by arrows in Fig. 4 . Theoretically, $E_{\mathrm{fb}}$ is estimated at $0.42 \mathrm{~V}$ vs. NHE when taking into account the calculated valence band position in surface $(0.58 \mathrm{~V}$ for a naked p-Si surface in $1 \mathrm{M} \mathrm{HCl})^{39}$ and the energy difference between $E_{\mathrm{vb}}$ and $E_{\mathrm{f}}$ (the Fermi level) for a silicon sample with $N_{\mathrm{a}}=1 \times 10^{16}$ $\mathrm{cm}^{-3}$. The values obtained in conditions, close to those of our experiments, vary from $0.37 \mathrm{~V}$ (in $\left.1 \mathrm{M} \mathrm{H}_{2} \mathrm{SO}_{4}\right)^{40}$ to $0.487 \mathrm{~V} v s$. NHE (in $0.1 \mathrm{M} \mathrm{HCl}) .^{41}$

When the native oxide layer is present, the flat band potential is $0.56 \pm 0.10 \mathrm{~V}$. The charge carrier density is two orders of magnitude higher than the expected value. The important contribution of surface states from the oxide can explain these differences with literature data. After formation of the $\mathrm{Si}-\mathrm{H}$ layer, the measured values of $E_{\mathrm{fb}}$ and $N_{\mathrm{a}}$ are in agreement with the expected values for p-type silicon. $E_{\mathrm{fb}}$ presents a relatively constant value of $0.46 \pm 0.04 \mathrm{~V}$ for a frequency ranging from $10^{3}$ to $10^{4} \mathrm{~Hz}$. The acceptor density obtained in this case $\left(N_{\mathrm{a}}=9.8 \times\right.$ $\left.10^{15} \mathrm{~cm}^{-3}\right)$ is in the range calculated from the conductivity of the wafer $\left(1.5 \times 10^{15}\right.$ to $1.5 \times 10^{16} \mathrm{~cm}^{-3}$ for $1-10 \Omega \mathrm{cm}$ p-type $\left.\mathrm{Si}\right)$. When a grafted layer is present, the flat band potential decreases by at least $0.18 \mathrm{~V}$. The $N_{\mathrm{a}}$ value is not significantly changed by the presence of a grafted layer, indicating that such a thin layer does not affect the sample conductivity.

\subsection{Modification of the surface properties of $\mathrm{p}$-Si with grafted layers}

With the $N_{\mathrm{a}}$ and $E_{\mathrm{fb}}$ values obtained from Mott-Schottky plots, the energy diagram of each electrode can be established according to the general principle described in Fig. 5. In addition to the known values for silicon $\left(E_{\mathrm{g}}=1.12 \mathrm{eV}, \chi_{\mathrm{si}}=\right.$
$4.05 \mathrm{eV}),{ }^{42}$ other parameters are required to obtain an energy band diagram. These include the work function $(\Phi)$, determined from the measured open circuit potential $\left(E_{\text {oc }}\right)$ for each sample, the band bending $\left(E_{\mathrm{bb}}\right)$ in the space charge layer and the shift of the Fermi level position toward the valence band, $\left|E_{\mathrm{vb}}-E_{\mathrm{f}}\right|_{\mathrm{vol}}$ (details of calculation are given in ESI†).

The position of the valence band at the surface, relative to the Fermi level $E_{\mathrm{vbs}}$, is another key parameter that allows a comparison between the XPS and electrochemical results. It can be calculated from the Mott-Schottky results according to:

$$
E_{\mathrm{vbs}}=E_{\mathrm{bb}}+\left|E_{\mathrm{vb}}-E_{\mathrm{f}}\right|_{\mathrm{vol}}
$$

For comparison, $E_{\mathrm{vbs}}$ can also be estimated from XPS measurements taking into account the measured $\mathrm{Si} 2 \mathrm{p}_{3 / 2}$ binding energy $\left(\mathrm{BE}^{m}\left(\mathrm{Si}_{2} \mathrm{p}_{3 / 2}\right)\right)$ with respect to the value for bulk silicon $\left(\mathrm{BE}^{v}\left(\mathrm{Si} 2 \mathrm{p}_{3 / 2}\right)=98.74 \pm 0.04 \mathrm{eV}\right) .{ }^{43}$

$$
E_{\mathrm{vbs}}=\mathrm{BE}^{m}\left(\operatorname{Si} 2 \mathrm{p}_{3 / 2}\right)-\mathrm{BE}^{v}\left(\operatorname{Si} 2 \mathrm{p}_{3 / 2}\right)
$$

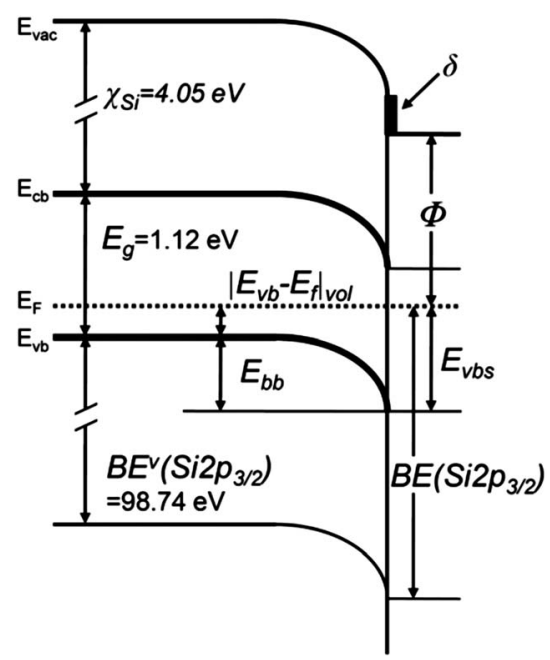

Fig. 5 Diagram of surface energy band position for a semiconductor and the different values accessible by XPS and electrochemical measurements.

Table 2 Electrochemical parameters obtained from Mott-Schottky plots and XPS measurements for the different modified and unmodified electrodes. Data from the

\begin{tabular}{|c|c|c|c|c|c|c|c|}
\hline $\mathrm{Si}-\mathrm{H}$ & $0.46 \pm 0.04$ & $9.8 \times 10^{15}$ & & $0.136 \pm 0.003$ & $0.52 \pm 0.04$ & $0.57 \pm 0.05$ & $-0.01 \pm 0.04$ \\
\hline Si-PPDA & $0.28 \pm 0.05$ & $1.6 \times 10^{16}$ & - & $0.154 \pm 0.003$ & $0.32 \pm 0.05$ & $0.32 \pm 0.07$ & $-0.20 \pm 0.05$ \\
\hline Si-ABA & $0.25 \pm 0.08$ & $8.3 \times 10^{15}$ & & $0.144 \pm 0.003$ & $0.31 \pm 0.08$ & $0.28 \pm 0.08$ & $-0.21 \pm 0.08$ \\
\hline $\begin{array}{l}\mathrm{Si}(\text { ref. } 40)^{c} \\
\left(1 \mathrm{~mol} \mathrm{~L}^{-1} \mathrm{H}_{2} \mathrm{SO}_{4}\right)\end{array}$ & 0.38 & $1.5 \times 10^{16}$ & $1-3 \times 10^{15}$ & & & & \\
\hline $\begin{array}{l}\text { Si (ref. 41 })^{c} \\
\left(0.1 \mathrm{~mol} \mathrm{~L}^{-1} \mathrm{HCl}\right)\end{array}$ & $0.49 \pm 0.04$ & $6.5 \times 10^{15}$ & $3 \times 10^{15}$ & & & & \\
\hline
\end{tabular}
literature are added for comparison

${ }^{a}$ Measurements performed in $1 \mathrm{~mol} \mathrm{~L}^{-1} \mathrm{HClO}_{4} \cdot{ }^{b} N_{\mathrm{a}}$ is calculated according $N=\left(r_{0} \mu_{\mathrm{p}} q\right)^{-1}$ with a hole mobility of $\mu_{\mathrm{p}}=416 \mathrm{~cm}^{2} \mathrm{~V}^{-1} \mathrm{~s}^{-1}$.

${ }^{c}$ Measurements on p-type $\mathrm{Si}(100)$. 
a) $\mathrm{Si}-\mathrm{H}$

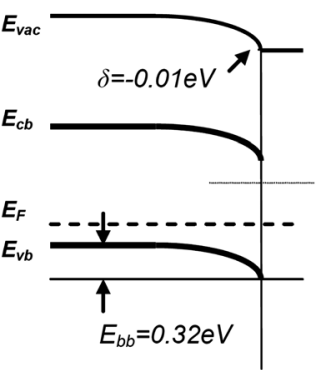

b) Si-PPDA

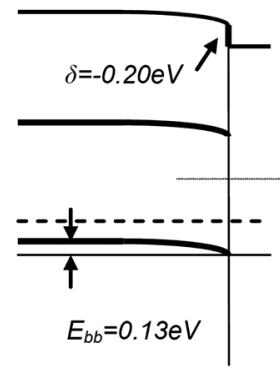

c) Si-ABA

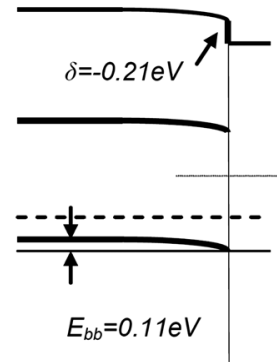

d) Si-AEA

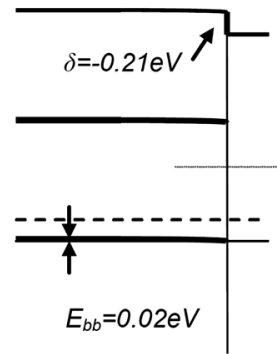

e) Si-NBD

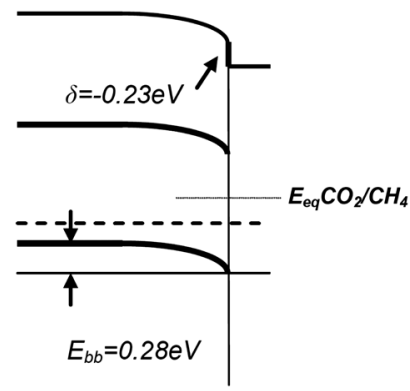

Fig. 6 Energy band diagram for the modified and unmodified silicon electrodes determined by XPS and Mott-Schottky measurements.

The $E_{\mathrm{vbs}}$ values obtained by the two methods, gathered in Table 2, are in good agreement for the silicon samples before and after modification by electrografting of aryl groups. With all these parameters, the surface potential step $(\delta)$ can be calculated according to:

$$
\delta=\Phi-E_{\mathrm{g}}-\chi_{\mathrm{si}}+E_{\mathrm{vbs}}
$$

It corresponds to the difference between the electron affinity at the surface or in the bulk of silicon. This parameter is expected to change with surface modification. The values for these parameters are presented in Table 2 and the obtained energy band diagrams of the different naked and modified silicon electrodes are gathered in Fig. 6.

The band bending is strongly reduced by the presence of an arylamine layer at the silicon surface when compared to naked $\mathrm{Si}-\mathrm{H}$ sample. This decrease is more important when the aliphatic chain is longer. This reduced $E_{\mathrm{bb}}$ value is another indication of the electronic passivation of the silicon/electrolyte interface in agreement with XPS results. In case of NBD, the band bending stays in the same range when compared to a $\mathrm{Si}-\mathrm{H}$ surface. It can be explained by the interaction between the nitro groups with the electrolyte.

For all grafted molecules, the surface potential step $\delta$ is shifted by $-0.2 \mathrm{eV}$. This shift of energy bands position can be explained by the filling of surface states and by the change of electrical dipole on the surface. The $\mathrm{Si}-\mathrm{H}$ polarization is different from the grafted molecule polarization. So the disappearance of $\mathrm{Si}-\mathrm{H}$ and the grafting of an organic layer change the surface potential. While $\delta$ value is in agreement with the dipole moment calculated for the amine-terminated molecules, it should be noticed that the dipole moment of 4-nitrobenzene (4.22 Debye in direction of the terminal nitro group) ${ }^{44}$ should induce a positive potential shift. The presence of hydroxylamine terminal groups induced by the cathodic potential applied during the grafting and the Mott-Schottky measurements can explain this difference. The non-ideal $\mathrm{Si}-\mathrm{H}$ and grafted surfaces provide another explanation. Indeed, the cumulative effect of individual molecules dipole arranged in an ideal monolayer is invoked to explain this macroscopic electrostatic potential shift, but in our case, and mainly for NBD grafting, the layers are nonideal monolayers and also consist in multilayers. Furthermore, as already shown by XPS and electrochemistry, a small amount of oxide is still present even after the treatment and can change the surface properties.

The interest of shifting the surface energy levels for photoelectrochemical applications is illustrated in Fig. 6, which shows the equilibrium potential for $\mathrm{CO}_{2} / \mathrm{CH}_{4}$ reaction $(-0.24 \mathrm{~V}$ vs. NHE at $\mathrm{pH} 7) .{ }^{45}$ The potential shift of $-0.2 \mathrm{eV}$ induced by the grafted layer induces a higher energy level of the conduction band that should increase the reaction rate or decrease the cathodic potential needed for photoelectrochemical reduction reactions.

\section{Conclusion}

Infrared spectroscopy and XPS confirmed the covalent grafting of the different amino and nitro terminated molecules by reduction of diazonium cations on p-type silicon surfaces. XPS measurements revealed that after several weeks of air exposure, the amount of oxide present in surface decreased significantly when an organic grafted layer is present. Electrochemical impedance spectroscopy measurements indicated the disappearance of surface states induced by the oxide layer in surface. The thickness of the grafted layers was estimated by XPS measurements and it appears that for the different amino terminated molecules, longer aliphatic chains yielded thinner layers due to the different reactivity of the in situ generated diazonium ions.

Combining electrochemical impedance spectroscopy and $\mathrm{X}$-ray photoelectron spectroscopy measurements to analyze the modified electrodes allows establishing the complete energy band diagram and, importantly, a correlation between the results obtained in vacuum and in an electrolyte. The presence of a grafted layer induces a surface potential shift of $-0.2 \mathrm{eV}$, which allows an increase of the conduction and valence bands energy levels in surface that can be helpful for reduction and photoreduction reactions. The band bending in the semiconductor is decreased by the presence of a grafted layer. In particular, for amino terminated molecules, the band bending is decreasing when the aliphatic chain is longer. This smaller band bending is an evidence of the reduction of the surface states density. 
Future work will focus on the control of the grafted layer thickness that appears to be a critical point for the surface properties. Furthermore, the modified electrodes could be tested as photocathode in a photoelectrochemical cell to study the effect of the shift of the surface energy level on the solar energy conversion efficiency.

\section{Acknowledgements}

Financial support from the Natural Sciences and Engineering Research Council of Canada is acknowledged for this project. Raymond Mineau (UQAM) and Dimitre Karpuzov (U. of Alberta) are thanked for their help in SEM and XPS measurements, respectively. The support of Opsun Technologies is also acknowledged.

\section{Notes and references}

1 J. Buriak, Chem. Rev., 2002, 102, 1271.

2 D. S. M. Wayner and R. A. Wolkow, J. Chem. Soc., Perkin Trans. 1, 2002, 2, 23.

3 M. G. Walter, E. L. Warren, J. R. McKone, S. W. Boettcher, Q. Mi, E. A. Santori and N. S. Lewis, Chem. Rev., 2010, 110, 6446.

4 R. Boukherroub, Curr. Opin. Solid State Mater. Sci., 2005, 9, 66. 5 D. R. Turner, J. Electrochem. Soc., 1958, 105, 402.

6 N. J. Harrick and K. H Beckman, Characterization of Solid Surfaces, Plenum, New York, 1974.

7 A. Tardella and J.-N. Chazalviel, Appl. Phys. Lett., 1985, 47, 334.

8 E. Yablonovitch, D. L. Allara, C. C. Chang, T. Gmitter and T. B. Bright, Phys. Rev. Lett., 1986, 57, 249.

9 M. Niwano, J.-I. Kageyama, K. Kinashi, J.-I. Sawahata and N. Miyamoto, Surf. Sci., 1994, 301, L245.

10 P. Hartig, J. Rappich and T. Dittrich, Appl. Phys. Lett., 2002, $80,67$.

11 B. P. Corgier, A. Laurent, P. Perriat, L. J. Blum and C. A. Marquette, Angew. Chem., Int. Ed., 2007, 46, 4108.

12 A. Mesnage, M. Abdel Magied, S. Pardis, N. Herlin-Boime, P. Jégou, G. Deniau and S. Palacin, J. Mater. Sci., 2011, 46, 6332.

13 R. Hunger, W. Jaegermann, A. Merson, Y. Shapira, C. Pettenkofer and J. Rappich, J. Phys. Chem. B, 2006, 110, 15432.

14 A. Vilan, A. Shanzer and D. Cahen, Nature, 2000, 404, 166.

15 S. C. Roy, O. K. Varghese, M. Paulose and C. A. Grimes, ACS Nano, 2010, 4, 1259.

16 J. Rappich, A. Merson, K. Roodenko, T. Dittrich, M. Gensch, K. Hinrichs and Y. Shapira, J. Phys. Chem. B, 2006, 110, 1332.

17 J. Charlier, E. Closus, C. Bureau and S. Palacin, J. Electroanal. Chem., 2008, 622, 238.

18 F. A. E. Hadj, A. Amiar, M. Cherkaoui, J.-N. Chazalviel and F. Ozanam, Electrochim. Acta, 2012, 70, 318.

19 K. Roodenko, F. Yang, R. Hunger, N. Esser, K. Hinrichs and J. Rappich, Surf. Sci., 2010, 604, 1623.

20 M. Delamar, R. Hitmi, J. Pinson and J. M. Saveant, J. Am. Chem. Soc., 1992, 114, 5883.
21 D. Bélanger and J. Pinson, Chem. Soc. Rev., 2011, 40, 3995.

22 J. Lyskawa and D. Bélanger, Chem. Mat., 2006, 18, 4755.

23 S. D. Babenko, A. A. Balakai, A. G. Lavrushko, Y. L. Moskvin and S. N. Shamaev, Russ. J. Electrochem., 2004, 40, 1205.

24 S. W. Boettcher, E. L. Warren, M. C. Putman, E. A. Santori, D. Turner-Evans, M. D. Kelzenberg, M. G. Walter, B. S. Brunschwig, H. A. Atwater and N. S. Lewis, J. Am. Chem. Soc., 2011, 133, 1216.

25 G. S. Higashi, Y. J. Chabal, G. W. Trucks and K. Raghavachari, Appl. Phys. Lett., 1990, 56, 656.

26 (a) T. Breton and D. Bélanger, Langmuir, 2008, 24, 8711; (b) J. Lyskawa, A. Grondein and D. Bélanger, Carbon, 2010, 48, 1271; (c) A. Grondein and D. Bélanger, Fuel, 2011, 90, 2684-2693.

27 D. Briggs and M. P. Seah, Practical Surface Analysis by Auger and X-ray Photoelectron Spectroscopy, Wiley, Chichester, U.K., 1st edn, 1983.

28 M. P. Seah, S. J. Spencer, F. Bensebaa, I. Vickridge, H. Danzebrink, M. Krumrey, T. Gross, W. Oesterle, E. Wendler, B. Rheinlander, Y. Azuma, I. Kojima, N. Suzuki, M. Suzuki, S. Tanuma, D. W. Moon, H. J. Lee, H. M. Cho, H. Y. Chen, A. T. S. Wee, T. Osipowicz, J. S. Pan, W. A. Jordaan, R. Hauert, U. Klotz, C. van der Marel, M. Verheijen, Y. Tarnminga, C. Jeynes, P. Bailey, S. Biswas, U. Falke, N. V. Nguyen, D. Chandler-Horowitz, J. R. Ehrstein, D. Muller and J. A. Dura, Surf. Interface Anal., 2004, 36, 1269.

29 P. Allongue, C. H. de Villeneuve, J. Pinson, F. Ozanam, J.-N. Chazalviel and X. Wallart, Electrochim. Acta, 1998, 43, 2791.

30 C. Henry de Villeneuve, J. Pinson, M. C. Bernard and P. Allongue, J. Phys. Chem. B, 1997, 101, 2415.

31 M. Gussoni and C. Castiglioni, J. Mol. Struct., 2000, $521,1$.

32 J. F. Moulder, W. F. Stickle, P. E. Sobol and K. D. Bomben, Handbook of X-ray photoelectron spectroscopy, Physical Electronics, Inc., Eden Prairie, 1995.

33 P. Allongue, C. Henry de Villeneuve, G. Cherouvrier, R. Cortès and M. C. Bernard, J. Electroanal. Chem., 2003, 550, 161.

34 C. Saby, B. Ortiz, G. Y. Champagne and D. Bélanger, Langmuir, 1997, 13, 6805.

35 A. Laforgue, T. Addou and D. Bélanger, Langmuir, 2005, 21, 6855.

36 P. Hartig, T. Dittrich and J. Rappich, J. Electroanal. Chem., 2002, 120, 524.

37 J. Charlier, E. Closus, C. Bureau and S. Palacin, J. Electroanal. Chem., 2008, 622, 238.

38 B. Ortiz, C. Saby, G. Y. Champagne and D. Bélanger, J. Electroanal. Chem., 1998, 455, 75.

39 Y. Nakato, T. Ueda, T. Egi and H. Tsubomura, J. Electrochem. Soc., 1987, 134, 353.

40 A. G. Muñoz, A. Moehring and M. M. Lohrengel, Electrochim. Acta, 2002, 47, 2751.

41 J. A. Bardwell, N. Draper and P. Schmuki, J. Appl. Phys., 1996, 79, 8761. 
42 S. M. Sze, Physics of Semiconductor Devices, Wiley, NewYork, 2nd edn, 1981.

43 F. J. Himpsel, G. Hollinger and R. A. Pollak, Phys. Rev. B: Condens. Matter Mater. Phys., 1983, 28, 7014.
44 J. Rappich, V. Y. Timoshenko and T. Dittrich, J. Electrochem. Soc., 1997, 144, 493.

45 R. Hinogami, Y. Nakamura, S. Yae and Y. Nakato, J. Phys. Chem. B, 1998, 102, 974. 